\title{
Negação da vontade e renúncia ao querer na Norma de Vincenzo Bellini: uma problematização schopenhaueriana
}

\author{
Denial of will and renunciation of desire in Vincenzo Bellini's Norma: a \\ Schopenhauerian problematization
}

\author{
Renato Nunes Bittencourt \\ Doutor em Filosofia pelo PPGF-UFRJ e Professor da FACC-UFRJ \\ E-mail: renatonunesbittencourt@gmail.com
}

\begin{abstract}
Resumo: 0 presente artigo procura opor a característica eminentemente afirmativa da Vontade à possibilidade da autonegação, ou, dito de outro modo, expor a contradição do fenômeno consigo mesmo. Desse dilaceramento íntimo, do intenso sofrimento pessoal, bem como do consequente elevar-se acima de sua individualidade, resultaria o repúdio de si mesmo. Do mesmo modo que mesmo no repúdio sempre se trata da atividade da vontade, também a supressão do querer presente na contemplação estética é analisada a partir da noção de que a vontade desaparece apenas da consciência, e não da contemplação em si mesma. Nesse sentido, os alvos, mesmo não sendo os da consciência comum, ainda são alvos sublimados da vontade.
\end{abstract}

Palavras-chave: Vontade; Consciência; Afirmação; Negação.
Abstract: This article seeks to oppose the eminently affirmative characteristic of the Will to the possibility of self-denial, or the contradiction of the phenomenon with itself. From this intimate laceration, from the intense personal suffering, as well as from the consequent elevation above its individuality, would result the repudiation of itself. In the same way that we are always talking about the activity of the will, even in negation, also the suppression of the Will present in the aesthetic contemplation is analyzed considering the notion that the will disappears only from the consciousness, and not from contemplation itself. In this sense, the targets, even though they are not those present in the common consciousness, are still sublimated targets of the Will.

Keywords: Will; Consciousness; Affirmation; Denial. 
Para Roberto Tibiriçá e Servio Tulio

\section{Introdução}

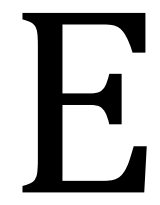
m tempos de crise institucional e do recrudescimento da barbárie por todas as partes do mundo, do obscurantismo e do irracionalismo no seio de uma sociedade que luta para viver a modernização democrática das suas instituições, o enfoque para a reflexão artística não se configura como uma fuga das contingências da realidade concreta, mas sim como uma técnica salubre de revitalização pessoal de modo a se enfrentar as insanidades da época histórica, legitimadas pela ordem injusta e pela mentalidade tacanha que fazem da indigência a sua tônica na constituição de uma sociedade doente. A fruição artística é um exercício de superação do espírito filisteu que está incrustrado na temerária corrupção política, que cunha o virulento reacionarismo existencial perante o impedimento da formação crítica dos sujeitos, estimulados tristemente a se aventurarem nos marcos infelizes da decadência como se mergulhassem em lama sagrada.

A ópera Norma, música de Vincenzo Bellini (libreto de Felice Romani), desde o feliz momento de minha primeira audição de tão maravilhosa obra me causa os mais poderosos deleites estéticos, servindo de inspiração para intensos momentos existenciais. Ao tomar ciência que Schopenhauer dedica algumas linhas filosóficas para comentar a essência dessa ópera não pude esconder o meu júbilo, e em consideração a essa oportuna relação pus-me a escrever esse texto, tentando honrar assim não apenas o legado da Norma, mas também a contribuição schopenhaueriana para o estudo da experiência trágica.

\section{O estatuto da tragédia em Schopenhauer}

Conforme os fundamentos da Metafísica do Belo em Schopenhauer, a contemplação do Belo, em Schopenhauer, se configura como um processo gradativo de mitigação da força da Vontade, na qual momentaneamente o sujeito suspende os apelos do seu querer, logo, do sofrer, e assim frui de maneira desinteressada as Ideias, somente apreendidas pelo puro sujeito do conhecimento, livre de qualquer inclinação: 
A arte repete as ideias eternas apreendidas por pura contemplação, o essencial e permanente de todas as aparências do mundo: de acordo com o estilo em que ela o repete, tem-se arte plástica, poesia ou música. Sua única origem é o conhecimento das ideias; seu único fim, a comunicação desse conhecimento ${ }^{1}$.

A tragédia, a culminação da arte poética, é a expressão mais acabada das belasartes, ao apresentar as Ideias da maneira mais clara possível. Nela as dores do mundo encontram a mais acabada das suas representações, mediante a exposição dos sofrimentos inenarráveis, o triunfo da iniquidade, a contradição da vontade consigo mesma. Um dos elementos mais universais da tragédia, em especial no seu revestimento cristão, é a certeza de que a vida não vale a pena ser vivida, e que somente a morte é capaz de permitir a superação as contradições do mundo. 0 caráter sublime da cena trágica consiste então em se revelar a grandeza moral daqueles que são derrotados perante as forças inexoráveis do mundo.

Quando o sujeito espiritualmente elevado sucumbe perante a maldade da tirania, o contraste estético entre a pequenez desse e a dignidade do primeiro gera um efeito arrebatador no espectador, pois a violência do mal não é capaz de dominar a alma do mártir, não obstante todos os horrores que são praticados contra sua integridade física. Contudo, mesmo que o desenlace trágico não nasça da oposição do herói perante o poder opressivo, o efeito ascético da obra não se perde. No fim, as inclinações pessoais são aniquiladas em decorrência de fatores externos que superam o ímpeto individual por afirmação de seu próprio querer. 0 pecado original é a individuação humana, e seus efeitos subsequentes são o egoísmo manifesto no desejo de realizar as demandas pessoais, custe o que custar. Segundo Schopenhauer,

No ápice da arte poética, tanto no que se refere à grandeza do seu efeito quanto à dificuldade da sua realização, deve-se ver a tragédia; e de fato ela assim foi reconhecida. Observe-se algo de suma significação para toda a nossa visão geral de mundo: o objetivo dessa suprema realização poética não é outro senão a exposição do lado terrível da vida, a saber, o sofrimento inominado, a miséria humana, o triunfo da maldade, o império cínico do acaso, a queda inevitável do justo e do inocente: em tudo isso encontra-se uma indicação significativa da índole do mundo e da existência. É o conflito da Vontade consigo mesma, que aqui desdobrado plenamente no grau mais elevado de sua objetidade, entra em cena de maneira aterrorizante. Esse conflito se torna visível no

${ }^{1}$ SCHOPENHAUER, A. MVR, I, § 36, p. 213.

Negação da vontade e renúncia ao querer na Norma de Vincenzo Bellini: uma problematização schopenhaueriana 
sofrimento da humanidade, em parte produzido pelo acaso e pelo erro, que se apresentam como os senhores do mundo e que, por causa de seus ardis que adquirem a aparência de intencionalidade, são personificados como destino: em parte esse sofrimento advém da humanidade mesma, por meio dos entrecruzados esforços voluntários dos indivíduos e da maldade e perversão da maioria. Em todos, o que vice e aparece é uma única mesma Vontade, cujas aparências, entretanto, combatem entre si e se entredevoram ${ }^{2}$.

Já no Tomo II de MVR, especificamente no capítulo 37 dos suplementos, Schopenhauer reforça essa argumentação, salientando que

O que confere a todo trágico, não importa a figura na qual apareça, a peculiar tendência à elevação é o brotar do conhecimento de que o mundo, a vida não pode proporcionar-nos prazer verdadeiro algum, portanto, nosso apego a ela não vale a pena: nisto consiste o espírito trágico: ele conduz por consequência à resignação ${ }^{3}$.

Após essas colocações conceituais, cabe a pergunta: A ópera é drama musicado ou música dramatizada? A ópera une a dramaticidade teatral com a musicalidade, tornando-se assim um novo gênero artístico. Argumentando conforme o pensamento schopenhaueriano, podemos afirmar que, quando a ópera expressa dramaticamente o processo ascético de negação da Vontade após vencer as paixões abrasadoras do querer, tanto melhor. Schopenhauer, no $§ 37$ do Tomo II de MVR, apresenta sua análise sobre a Norma de Vincenzo Bellini, em especial no dueto Qual cor tradisti.

Mencione-se aqui que o autêntico efeito trágico da catástrofe, portanto, a resignação e elevação espiritual do herói por ele produzida, raras vezes é tão puramente motivado e nitidamente expresso quanto na ópera Norma, em que ele ocorre no dueto Qual cor tradisti, qual cor perdesti, no qual a conversão da Vontade é nitidamente indicada através da súbita calma introduzida na música. De modo geral, essa peça - sem contar a sua excelente música, bem como a dicção, que só pode ser a de um libreto -, se considerada só do ponto de vista de seus motivos e da sua economia interna, é uma tragédia de suma perfeição, um verdadeiro modelo de combinação trágica dos motivos, de progressão e desenlace trágicos da ação, assim como do efeito destes sobre a disposição moral dos heróis, que se eleva por sobre o mundo, o que também é transmitido ao espectador: de fato, o efeito alcançado é tanto mais incontroverso e mais característico da verdadeira essência da tragédia porque aqui não

\footnotetext{
${ }^{2}$ SCHOPENHAUER, A. MVR, I, § 51, p. 292-293.

${ }^{3}$ SCHOPENHAUER, A. MVR, II, § 37, p. 520.

Negação da vontade e renúncia ao querer na Norma de Vincenzo Bellini: uma problematização schopenhaueriana
} 
aparecem os cristãos nem a disposição moral cristã 4 .

A Norma de Bellini apresenta de maneira exemplar esse processo, em especial nas figuras dos seus protagonistas, a sacerdotisa gaulesa Norma e o procônsul romano Pollione. Conforme a narrativa dramática, ambos foram outrora amantes e dessa relação tiveram dois filhos. A tragédia musical se inicia com a relação amorosa rompida, e Pollione já enuncia seu amor por Adalgisa, virginal sacerdotisa, enquanto Norma persevera em reconquistar o amor perdido, e essa intriga é o motor dessa flutuante narrativa passional. Para compreendermos a reviravolta final da ópera, foco essencial de nosso trabalho, apresento nos parágrafos posteriores alguns trechos que resumem a narrativa com comentários que visam estabelecer convergências axiológicas entre a teoria schopenhaueriana da tragédia e a intensidade dramática da Norma.

\title{
A Norma de Bellini, uma ópera afim ao espírito schopenhaueriano
}

A abertura (Sinfonia) da ópera apresenta uma bela intercalação de traços marciais e cantábiles, procedimento que acentua a tensão dramático-musical do que virá em seguir. Bellini apresenta alguns temas cruciais da ópera em passagens da abertura, preparando assim o espectador para a inebriante dramaticidade que se desenrolará nos eventos trágicos de Norma. Não se trata assim de mera música convencional para se preparar a orquestra, mas a transmissão de impressões estéticas absolutamente sintonizadas com o espírito conflitante da ópera.

No início do Ato I, Oroveso, pai de Norma e chefe dos druidas, reúne os guerreiros gauleses no bosque sagrado para a ansiada luta decisiva contra os invasores romanos, aguardando um sinal positivo dos deuses para a consecução de tal fim. Contudo, Norma entra em cena portando o discurso da paz e da conciliação, contrariando as expectativas dos furibundos gauleses:

\author{
NORMA \\ Sediziose voci, voci di guerra \\ Avvi chi alzarsi attenta \\ Presso all'ara del Dio? \\ V'ha chi presume \\ Dettar responsi alla veggente Norma,
}

${ }^{4}$ SCHOPENHAUER, A. MVR, II, § 37, p. 522-523.

Negação da vontade e renúncia ao querer na Norma de Vincenzo Bellini: uma problematização schopenhaueriana 
E di Roma affrettar il fato arcano?

Ei non dipende, no, non dipende

Da potere umano.

\section{OROVESO}

E fino a quando oppressi

Ne vorrai tu?

Contaminate assai

Non fur le patrie selve

E i templi aviti

Dall'aquile latine?

Omai di Brenno oziosa

Non può starsi la spada.

Após enfatizar a paz como o propósito divino para os druidas e contrariar assim o senso comum, Norma entoa a ária Casta Diva, suavíssima oração em honra da Lua, abrandando momentaneamente os corações dos guerreiros celtas graças ao poder lenitivo desse doce cântico:

\section{NORMA}

Io ne' volumi arcani leggo del cielo,

In pagine di morte

Della superba Roma è scritto il nome.

Ella un giorno morrà,

Ma non per voi.

Morrà pei vizi suoi,

Qual consunta morrà.

L'ora aspettate, l'ora fatal

Che compia il gran decreto.

Pace v'intimo ;

E il sacro vischio io mieto.

Casta Diva, che inargenti

Queste sacre antiche piante,

Al noi volgi il bel sembiante,

Senza nube e senza vel!

\section{OROVESO E CORO}

Casta Diva, che inargenti

Queste sacre antiche piante, Al noi volgi il bel sembiante, Senza nube e senza vel!

\section{NORMA}

Tempra, o Diva,

Tempra tu de' cori ardenti,

Tempra ancora lo zelo audace.

Spargi in terra quella pace

Che regnar tu fai nel ciel. 


\section{OROVESO E CORO}

Diva, spargi in terra

Quella pace che regnar Tu fai nel ciel.

As intervenções posteriores de Norma até sua saída de cena na primeira parte do Ato I permanecem afins ao seu constante propósito plácido de paz, e mesmo sua angústia amorosa pelo anseio de reatar sua relação com Pollione não extravasa em discurso inflamado, mas animicamente contido, delineando assim os até então traços racionais de seu caráter:
Ah! bello a me ritorna
Del fido amor primiero,
E contro il mondo intiero
Difesa a te sarò.
Ah! bello a me ritorna
Del raggio tuo sereno
E vita nel tuo seno
E patria e cielo avrò.

Encerrando a primeira parte do Ato I, temos então a entrada em cena de Adalgisa e o entoo de seu cântico virginal, interrompido pela chamada apaixonada de Pollione, que a invita a abandonar a Gália e partir com ele para Roma e suas delícias. Adalgisa, dividida moralmente entre os seus votos sagrados aos deuses gauleses e o seu amor cândido por Pollione, este, por sua vez, disposto a abandonar Norma para sempre e assim viver sua paixão extasiante pela donzela em sua saudosa terra natal. Porém, a recusa inicial de Adalgisa é o mote dramático do dueto Va Crudele, na qual Pollione se lamuria pela decisão da donzela ratificar os seus votos sagrados em detrimento desse amor temerário:

\section{ADALGISA \\ (vedendo a Pollione) \\ Oh, tu qui!}

POLLIONE

Che veggo? Piangevi tu?

ADALGISA

Pregava.

Ah! T'allontana, pregar mi lascia! 
Atroce, crudele,

Avverso al tuo desire e al mio.

0 mia diletta!

Il Dio che invocar devi è Amore.

ADALGISA

(si allontana da lui)

Amor! Deh! Taci,

Ch'io più non t'oda!

\section{POLLIONE}

E vuoi fuggirmi?

E dove fuggir vuoi tu ch'io non ti segua?

ADALGISA

Al tempio, ai sacri altari

Che sposar giurai.

POLLIONE

Gli altari? E il nostro amor?

ADALGISA

Io l'obliai.

POLLIONE

Va, crudele, al Dio spietato

Offri in dono il sangue mio.

Tutto, ah, tutto ei sia versato,

Ma lasciarti non poss'io,

No, nol posso!

Sol promessa al Dio tu fosti,

Ma il tuo core a me si diede.

Ah! Non sai quel che mi costi

Perch'io mai rinunzi a te.

Ah! Non, ecc.

\section{ADALGISA}

E tu pure, ah, tu non sai

Quanto costi a me dolente!

All'altare che oltraggiai

Lieta andava ed innocente,

Sì, sì, v'andava innocente.

Il pensiero al cielo ergea

E il mio Dio vedeva in ciel!

Or per me spergiura e rea

Cielo e Dio ricopre un vel!

O extenso dueto atinge o clímax quando ocorre diálogos rápidos entre Pollione e Adalgisa, um trecho que interpretamos como a manifestação lúbrica da Vontade no assédio de Pollione a Adalgisa, com a música de Bellini descrevendo com absoluta 
precisão esse estado de excitação anímica, em um ritmo orquestral crescente que arrebata o espectador/ouvinte, tal como a simulação de uma pulsação sanguínea que deseja ser saciada imediatamente e que se amplifica a cada tentativa de se esquivar dessa força vulcânica:

\author{
ADALGISA \\ (Fra sè) \\ Ciel! Così parlar l'ascolto \\ Sempre, ovunque, al tempio istesso! \\ Con quegli occhi, con quel volto, \\ Fin sull'ara il veggo impresso. \\ Ei trionfa del mio pianto, \\ Del mio duol vittoria ottien. \\ Ciel! Mi togli al dolce incanto, \\ 0 l'error perdona almen!
}

\title{
POLLIONE
}

Ah! Vieni!

ADALGISA

Deh! Pietà!

POLLIONE

Ah! Deh! Vieni, ah, vieni, o cara!

ADALGISA

Ah! Mai!

POLLIONE

Crudel! E puoi lasciarmi?

ADALGISA

Ah! Per pietà, mi lascia!

POLLIONE

Così, così scordarmi!

ADALGISA

Ah! Per pietà, mi lascia!

Após finalmente ceder aos ardentes apelos amorosos de Pollione, Adalgisa enfim se livra dos votos de castidade e pode gozar da potência imanente do amor, e o poslúdio orquestral, de tom alegre e vivaz, também representa com bastante brilhantismo o enfim realizado enlace do casal e as preliminares da sua conjunção amorosa. 0 que as palavras não descrevem convenientemente, a música o faz com todo o seu poder extralinguístico. 
Na primeira cena do Ato II Norma toma ciência de que Adalgisa e Pollione são amantes. A constante candura da sacerdotisa se esvai e toda sua ira contra ambos explode. Pollione, por sua vez, experiente na arte de amar, se esforça novamente em seduzir a jovem aprendiz e a invita a juntos irem para Roma desfrutarem uma nova vida. Contudo, Adalgisa recua e prefere permanecer fiel ao seu propósito religioso. A seleção abaixo representa bem a tensão entre os três personagens, o rancor, o ódio e a frustração que os anima:

\begin{abstract}
ADALGISA
(supplichevole a Norma)

Ah! Non fia ch'io costi

Al tuo core si rio dolore!

Ah, sian frapposti e mari e monti

Fra me sempre e il traditore. Ah!
\end{abstract}

NORMA

Maledetto dal mio sdegno

Non godrai d'un empio amore!

ADALGISA

Soffocar saprò i lamenti,

Divorare i miei tormenti;

Morirò perchè ritorno

Faccia il crudo ai figli, a te! ecc.

\section{POLLIONE}

Dio non v'ha che mali inventi De' miei mali, ah, più cocenti!

Maledetto io fui quel giorno

Che il destin m'offerse a te.

Maledetto io fui per te!

O finale do Ato I é uma tempestade de afetos conflituosos do trio de protagonistas em absoluta divergência de posições, e o chamamento do coro dos guerreiros gauleses (externo ao palco) pela presença de Norma para que esta vá ao bosque sagrado realizar o serviço divino em um ritmo agitado tal como uma bacanal poderia ser interpretada como uma manifestação dramática do conflito da Vontade consigo mesma.

No Ato II, a segunda cena apresenta os elementos dramáticos mais intensos para o progresso da tragédia operística. 0 amor de Norma por Pollione é capaz de fazê-la perder todo bom senso, seja na condução dos seus ofícios religiosos, manipulando o poder sacerdotal da maneira que lhe convém, seja no controle sobre as ações dos 
guerreiros gauleses, que aguardam as "instruções" divinas para que possam ou não agir. Enquanto Norma ainda acredita no retorno amoroso de Pollione, a sacerdotisa clama por paz, mas quando a situação se torna irreversível ela não hesita em brandir o escudo sagrado, chamando as hordas para a guerra:

\section{OROVESO E CORO}

Guerra, guerra! Le galliche selve Quante han quercie producon guerrier: Qual sul gregge fameliche belve, Sui Romani van essi a cader!

\section{NORMA}

Sangue, sangue! Vendetta!

Strage, strage!

\section{OROVESO E CORO}

Sangue, sangue! Le galliche scuri Fino al tronco bagnate ne son! Sovra il flutti dei Ligeri impuri Ei gorgoglia con funebre suon!

\section{NORMA}

Guerra, guerra!

Sangue, sangue! Vendetta!

\section{OROVESO E CORO}

Strage, strage, sterminio, vendetta! Già comincia, si compie, s'affretta. Come biade da falci mietute Son di Roma le schiere cadute!

\section{NORMA}

Strage, strage!

\section{OROVESO E CORO}

Tronchi i vanni, recisi gli artigli. Abbattuta ecco l'aquila al suol!

A mirare il trionfo de' figli

Ecco il Dio sovra un raggio di sol!

Na segunda cena do Ato II, após Pollione ser capturado por ousar invadir o templo sagrado para raptar Adalgisa, Norma outorga para si o poder sagrado de interrogar o profano, para assim de modo frio e calculista dominar o seu odioso amado. O primeiro dueto de Norma e Pollione se inicia sobriamente:

\section{NORMA}

In mia man alfin tu sei: 
Niun potria spezzar tuoi nodi.

Io lo posso.

POLLIONE

Tu nol dei.

NORMA

Io lo voglio.

POLLIONE

E come?

NORMA

M'odi.

Pel tuo Dio, pei figli tuoi,

Giurar dei che d'ora in poi

Adalgisa fuggirai,

All'altar non la torrai,

E la vita io ti perdono,

$\mathrm{E}$ mai più ti rivedrò.

Giura.

POLLIONE

No. Si vil non sono.

\section{NORMA}

Giura, giura!

POLLIONE

Ah! Pria morrò!

\section{NORMA}

Non sai tu che il mio furore

Passa il tuo?

\section{POLLIONE}

Ch'ei piombi attendo.

\section{NORMA}

Non sai tu che ai figli in core Questo ferro?

Após intercalações entre os protagonistas, temos o belíssimo e intenso dueto iniciado pela gozosa esperança de Norma em muito brevemente ver sofrer Pollione, extravasando assim o seu cruento ódio contra aquele que tanto ama:

\section{NORMA}

Preghi alfine? Indegno! È tardi.

Nel suo cor ti vo' ferire, 
Sì, nel suo cor ti vo' ferire! Già mi pasco ne' tuoi sguardi, Del tuo duol, del suo morire, Posso alfine, io posso farti Infelice al par di me! posso farti alfin, ecc.

\section{POLLIONE}

Ah! T'appaghi il mio terrore! $\mathrm{Al}$ tuo piè son io piangente! In me sfoga il tuo furore, Ma risparmia un'innocente! Basti, basti a vendicarti Ch'io mi sveni innanzi a te!

\section{NORMA}

Nel suo cor ti vo' ferire!

POLLIONE

Ah! T'appaghi il mio terrore!

\section{NORMA}

No, nel suo cor!

\section{POLLIONE}

No, crudel!

\section{NORMA}

Ti vo' ferire!

\section{POLLIONE}

In me sfoga il tuo furore, Ma risparmia un'innocente!

\section{NORMA}

Già mi pasco ne' tuoi sguardi, Del tuo duol, del suo morire; posso alfine, io posso farti infelice al par di me

POLLIONE

Ah! Crudele!

\section{NORMA}

posso farti alfin, posso farti infelice al par di me, ecc.

\section{POLLIONE}

Basti, basti il mio dolore Ch'io mi sveni innanzi a te! Basti, basti a vendicarti, ecc.

Quem poderia postular que após tal explosão de afetos teríamos a transformação 
surpreendente da disposição volitiva de Norma? A flutuação de estados anímicos, representados genialmente pela música de Bellini, é um dos trunfos dramáticos da ópera, fazendo da mesma o seu merecido lugar de destaque entre as grandes obras da humanidade. Na Norma não existe oposição entre bondade e maldade na composição dos caracteres de todos os personagens, e os protagonistas são figuras marcadas pela flutuação de ânimo, pela paixão desenfreada que comumente que nelas exerce um ímpeto egoísta de luta por satisfação dos seus desejos. Norma, em momento de grande anseio por vingança, ousa atentar contra as vidas dos seus próprios filhos, mas desiste de tal intento. Os personagens são todos convenientemente humanizados em seus atos, efeito dramático que fortalece ainda mais a credibilidade da obra e sua fruição estética. Não há intervenção sobrenatural na tragédia em favor da resolução dos conflitos, atiçando-se então as contradições dramáticas. Segundo o parecer de Sergio Casoy,

Os contrastes de amor e ódio, melancolia e alegria feroz, instinto maternal e desejo de vingança são magnificamente descritos por um Bellini que atingiu sua plenitude como compositor. Suas melodias inspiradas e sublimes, de grande carga emocional, são desprovidas de artifícios e de retórica vazia, e nos falam diretamente ao coração ${ }^{5}$.

É de grande pertinência destacar que a teoria schopenhaueriana da tragédia fora apresentada anos antes da realização da Norma de Bellini, o que evidencia a capacidade do filósofo em se apropriar criticamente do sentido de uma obra e transformá-la como exemplo de sua teoria. Contextualizemos: o tomo I de MVR foi publicado em 1818, a primeira apresentação de Norma é de 1831, e o tomo II de MVR (suplementos), na qual encontra-se a bela explanação sobre a ópera, é de 1844. 0 grande paradigma operístico schopenhaueriano na redação do tomo I de MVR era Rossini, fecundo criador não apenas de óperas bufas, mas também de óperas dramáticas/trágicas. Bellini, por decorrência de sua morte precoce, produziu muito menos do que Rossini, mas suas obras conquistaram merecido lugar na história da ópera. Não apenas Schopenhauer estava plenamente atualizado acerca da vida cultural mundial, como também reforça sua concepção sobre o trágico através de uma obra de grande impacto na história da música operística. Talvez a única ópera posterior de motivo pagão que apresente a essência cristã em seu encadeamento dramático final seja a Aida de Verdi, inclusive fazendo-se uso de

${ }^{5}$ CASOY, S. Óperas e outros cantares, p. 71.

Negação da vontade e renúncia ao querer na Norma de Vincenzo Bellini: uma problematização schopenhaueriana 
expressões completamente afins ao espírito cristão, tal como podemos constatar nos versos da grande protagonista:

\author{
0 terra, addio; \\ addio, valle di pianti, \\ sogno di gaudio \\ che in dolor svanì. \\ A noi si schiude il ciel \\ e l'alme erranti \\ volano al raggio dell'eterno dì.
}

Contudo, não obstante todo o mérito musical da ópera verdiana, não encontramos o mesmo impacto transcendente da conversão anímica magistralmente musicada por Bellini em Qual cor tradisti. Na Aida, os protagonistas mantêm constância amorosa no decorrer de toda a obra, lutando contra as adversidades concretas com a força do afeto, até o trágico final. Na Norma os protagonistas permanecem em desentendimento mútuo até a cena final da ópera, quando enfim, após a catarse de ódio e de rancor que os desunia, enfim modificam beatificamente suas disposições de ânimo e tornam a se amar, livres de todos os entraves, em um amor redentor e apaziguador que os conforta na hora da morte que eles mesmos conscientemente buscaram, como forma de se livrarem dos seus tormentos existenciais e para que se purifiquem dos seus erros passados. Façamos enfim a análise desse trecho:

\title{
NORMA
}

Qual cor tradisti, qual cor perdesti Quest'ora orrenda ti manifesti. Da me fuggire tentasti invano, Crudel Romano, tu sei con me. Un nume, un fato di te più forte Ci vuole uniti in vita e in morte. Sul rogo istesso che mi divora, Sotterra ancora sarò con te. ${ }^{6}$

\section{POLLIONE}

(A Norma)

Ah! Troppo tardi t'ho conosciuta!

Sublime donna, io t'ho perduta!

\section{NORMA}

Qual cor tradisti, ecc.

\footnotetext{
${ }^{6}$ Ouso dizer, conforme a conceituação schopenhaueriana, que é a Vontade em seu processo de autonegação a força operadora dessa união que suprime a contradição moral entre os protagonistas padecentes.

Negação da vontade e renúncia ao querer na Norma de Vincenzo Bellini: uma problematização schopenhaueriana
} 
POLLIONE

Col mio rimorso è amor rinato,

Più disperato, furente egli è!

Moriamo insieme, ah, sì, moriamo!

NORMA

Quest'ora orrenda...

\section{POLLIONE}

L'estremo accento sarà ch'io t'amo.

Ma tu morendo, non m'abborrire,

Pria di morire, perdona a me!

\section{OROVESO E CORO}

Oh! In te ritorna, ci rassicura!

\section{NORMA}

(ai Sacerdoti)

Io son la rea.

\section{OROVESO E CORO}

Canuto padre te ne scongiura,

\section{POLLIONE}

(accostandosi a Norma)

Non m'abborrire

\section{NORMA}

(A Pollione)

Qual cor perdesti,

\section{OROVESO E CORO}

Di che deliri, di che tu menti, Che stolti accenti uscir da te

\section{POLLIONE}

Moriamo insieme! Ah, sì, moriam.

\section{NORMA}

quest'ora orrenda tel dica

\section{OROVESO E CORO}

Il Dio severo che qui t'intende

POLLIONE

Ah! Perdona!

\section{OROVESO E CORO}

Se stassi muto, se il tuon sospende,

\section{POLLIONE}

Ah! T'ho perduta 


\section{NORMA}

Sì, e per sempre.

\section{OROVESO E CORO}

Indizio è questo, indizio espresso

\section{POLLIONE}

Sublime donna!

\section{NORMA}

Quest'ora orrenda tel dica

\section{POLLIONE}

Perdona, perdon.

\section{OROVESO E CORO}

Che tanto eccesso punir non de', Ah no, che il Dio punir non de' ecc.

\section{NORMA}

Crudel! per sempre, ah sì, crudel!

\section{POLLIONE}

Che feci, oh ciel!

Bellini utiliza o tempo musical de 4/4 nesse trecho crucial, produzindo um efeito de desprendimento existencial, tal como a alma que se prepara para abandonar a carnalidade rumo aos planos etéreos. 0 belíssimo cântico de Norma soa como uma elegia de uma pessoa consciente de sua morte iminente. Para Schopenhauer, nessa cena expressa-se dramaticamente e musicalmente a própria negação da Vontade, indicada pela suavidade sonora que bruscamente se manifesta no jogo cênico, até então intenso, atribulado, contraditório, egoísta. Com efeito, a protagonista, após perseverar ardentemente pela realização de sua vingança contra seu ex-amante, Pollione, pretendendo inclusive assassinar os filhos que teve com este e ordenar ao sacrifício a jovem Adalgisa, a nova paixão daquele, encerra de forma abrupta tal intento ao ela mesma se imputar como a escolhida pela divindade para o ritual. 0 êxtase do ódio, que se manifestava tão violentamente em seu ânimo e confundia o seu entendimento, se transforma em renúncia ao agir, dando-lhe serenidade diante de seu destino fatal. Analisando com os conceitos schopenhauerianos, percebemos nesse momento da ópera a autonegação da Vontade, decorrente da compreensão de que os percalços da vida são desprovidos de qualquer sentido, e a morte é o fim dos tormentos existenciais. Por isso 
Norma caminha tão plácida para o sagrado fogo consumidor, pois se libertou dos motivos que até outrora lhe atormentavam. Sua última preocupação é recomendar ao seu pai Oroveso, sacerdote dos druidas, que os filhos em breve órfãos recebam os cuidados necessários. Todavia, analisando a ópera a nível filosófico, poderíamos afirmar que a mesma já poderia se encerrar ao término da ária, pois a questão ontológica fundamental, a supressão da Vontade, já havia se concretizado, sendo o final da ópera, ainda que dramaticamente convincente e musicalmente arrebatador, apenas uma necessidade estética para culminar a tragédia.

\section{CORO}

Vanne al rogo ed il tuo scempio

Purghi l'ara e lavi il tempio,

Maledetta estinta ancor!

As vozes do coro amaldiçoam Norma na hora da morte, expressão cruenta de sua impiedade e flutuação de ânimo, mas isso pouco efeito moral pode causar na sacerdotisa, pois ela se libertou da vontade de viver. Assim, Norma morre redimida e destemida, assim como o impetuoso Pollione:

\section{POLLIONE}

Il tuo rogo, o Norma, è il mio!

Là più santo

Incomincia eterno amor!

Apesar dos motivos pagãos da ópera, esta, na verdade, apresenta um substrato razoavelmente afim com o espírito cristão, manifestando assim um grau de elevação moral muito maior, pois no fundo expressa o aniquilamento da vontade de vida individualizada em pessoas egoístas que subitamente reorientam os motivos das suas ações, suprimindo internamente o afã de satisfazer suas inclinações pessoais mediante a renúncia ao que lhes proporcionaria sensivelmente razoável grau de regozijo. Norma é muito mais bem delineada dramaticamente do que Pollione, por isso sua transformação interior na cena decisiva é tão impactante para o apreciador de ópera, pois vemos seu ódio (que no fundo nasce de um amor frustrado) abruptamente desaparecer e se tornar constatação da nulidade da vida, desalento para com o mundo, e assim seu caráter se adoça, exigindo-lhe o sacrifício pessoal para enfim se livrar da sua dor moral, ou melhor, 
dor ontológica.

Ao reconhecer a dignidade sublime de Norma e se inspirar moralmente por ela, Pollione também sofre essa conversão de ânimo, perdendo sua paixão inflamada que tantas atribulações lhe causaram outrora e reconhecendo finalmente na pessoa de Norma o seu genuíno amor, agora desvinculado do desejo carnal. Norma e Pollione morrem como mártires, mas não como os cristãos que eram dizimados por tiranos contrários aos princípios religiosos daqueles, mas sim como os oprimidos pelo ímpeto cego do querer que, no entanto, intuem a miséria da existência e cessam radicalmente a fonte dolorosa do desejo, não lhes restando outra alternativa viável do que o aniquilamento pessoal no fogo consumidor que dissipa a matéria corpórea. Talvez somente uma morte tão estrondosa possa servir de extinção de duas vidas tão intensas, apesar de que o ardor que lhes inflamava já fora anteriormente suprimido. A morte é a redenção para os seus tormentos, expressão concreta da impossibilidade de ambos obterem em vida a tão ansiada felicidade. Quando a vontade de viver se dissipa e ambos constatam a impossibilidade de encontrarem a satisfação dos seus desejos amorosos, a morte se torna para ambos o melhor fim. Pollione, que até então desprezava sua examante, modifica também sua polaridade na hora extrema, amando-a novamente, em um amor puro, desprovido dos laços da sensibilidade, um amor espiritualizado, ascético, no qual a iminência da morte acentua sua intensidade e êxtase. Com efeito, inebriados por essa reconfiguração amorosa, ambos caminham juntos para a aniquilação física, serenos, todavia, pela cessação dos seus tormentos existenciais.

Norma é assim uma ópera afim ao espírito cristão em sua expressão genuína tal como imputado por Schopenhauer, pois apresenta a negação da vontade, a renúncia ao agir, a adesão plácida, após sucessivas contradições e atribulações pessoais, ao morrer, pois a vida não permite a satisfação plena das aspirações individuais. Somente a morte encerra as contradições individuais.

\section{Considerações finais}

Será a ópera Norma a moderna realização do modelo de tragédia que se pauta pela negação da Vontade em um viés estético convincente? 0 efeito dramático da conversão da Vontade em sua supressão ontológica ocorre precisamente pela ausência de traços moralistas na ópera, como se esta fosse uma exposição pedagógica dos vícios e 
das virtudes humanas em embate pela redenção humana. No sistema schopenhaueriano, é a tragédia o elo entre a Metafísica do Belo (e seu processo de elevação da consciência humana para além dos limites da representação) e a Metafísica da Ética, onde se obtém a superação definitiva do querer pela renúncia ao querer, pela ascese, pela negação da Vontade. Todas as fruições contemplativas proporcionadas pelas belas artes suspendem provisoriamente o querer humano, mas somente a tragédia, em especial a de motivo cristão, é capaz de efetuar a radicalidade da ruptura pessoal com os apelos do mundo. Contudo, ouso dizer que é apenas a ópera trágica que realiza de maneira mais acabada esse processo de conexão entre a Metafísica do Belo e a Metafísica da Ética, pois justamente se apropria da musicalidade como recurso estético para a apresentação dos seus conteúdos.

\section{Referências bibliográficas}

CASOY, Sergio. Óperas e outros cantares. São Paulo: Perspectiva, 2006.

SCHOPENHAUER, Arthur. O mundo como vontade e como representação. Tomo I. Trad. Jair Barboza. São Paulo: Ed. UNESP, 2015.

O mundo como vontade e como representação. Tomo II. Trad. Jair Barboza. São Paulo: Ed. UNESP, 2015. 